\title{
Cooperative interaction of rich and poor can be catalyzed by intermediate climate targets
}

\section{A letter}

\author{
Manfred Milinski • Torsten Röhl • Jochem Marotzke
}

Received: 9 August 2011 / Accepted: 1 October 2011/Published online: 15 October 2011

(C) The Author(s) 2011. This article is published with open access at Springerlink.com

\begin{abstract}
International climate negotiations that aim at reducing global greenhouse gas emissions are strongly influenced by a conflict between rich and poor countries and by a lack of consensus about the urgency of emission reduction measures. We have previously in an experimental game characterised the implied challenge of avoiding dangerous climate change as the "collective-risk social dilemma". Here we introduce heterogeneous wealth and two time horizons into the collective-risk social dilemma game. We show that rich players are willing to substitute for missing contributions by the poor, provided the players collectively face intermediate climate targets that, if not reached, are potentially followed by simulated intermediate costly climate risks. However, despite some increase in the contributions of the rich against the final collective target, the final target is reached less often than the intermediate target. Our results provide experimental evidence that similar, intermediate time horizons between climate risks and climate change mitigation planning are a necessary, though not sufficient, component of successful climate negotiations.
\end{abstract}

Electronic supplementary material The online version of this article (doi:10.1007/s10584-011-0319-y) contains supplementary material, which is available to authorized users.

M. Milinski $(\bowtie)$

Department of Evolutionary Ecology, Max Planck Institute for Evolutionary Biology, August-Thienemann-Strasse 2, 24306 Ploen, Germany

e-mail: milinski@evolbio.mpg.de

T. Röhl

Research Group Evolutionary Theory, Max Planck Institute for Evolutionary Biology,

August-Thienemann-Strasse 2, 24306 Ploen, Germany

e-mail: roehl@evolbio.mpg.de

J. Marotzke

Department "The Ocean in the Earth System", Max Planck Institute for Meteorology, Bundesstrasse 53,

20146 Hamburg, Germany

e-mail: jochem.marotzke@zmaw.de 


\section{Introduction}

The target to limit the anthropogenic rise in global-mean surface temperature to $2^{\circ} \mathrm{C}$ compared to pre-industrial times can only be reached if by year 2050 the global greenhouse gas (GHG) emissions are reduced by more than 50\% compared to year 2000 emissions (Meinshausen et al. 2009; Roeckner et al. 2010). The existence of a collective target that needs to be reached-here, the reduction in global GHG emissions-combined with the possibility and fear of free-riding define what we have previously identified as "the collective-risk social dilemma" (Milinski et al. 2008; see also Raihani and Aitken 2011; Santos and Pacheco 2011). The 15th Conference of Parties (COP15) in Copenhagen in December 2009 has shown that some of the difficulty of solving the GHG emissions reduction social dilemma lies in the interaction of rich and poor countries and their conflicting mutual expectations of each other (Anonymous 2009). COP15 and the months following have also shown a tendency in governments to regard climate change as a problem of the distant future that therefore does not have urgency. But some consequences of climate change, such as increased occurrence of heat waves and droughts, could happen well before 2050 (Meehl et al. 2007). Here, we investigate experimentally whether the collective-risk social dilemma is harder or easier to solve if we add to our experimental procedure two crucial ingredients of the global GHG emissions reduction negotiations: the interaction of rich and poor and the inclusion of intermediate climate targets and climate risks.

Rich countries have more wealth at stake than poor countries if the collective target is missed and might hence agree to invest more in order to protect their greater wealth. Conversely, investing the same amount as the rich would cost the poor a comparatively higher proportion of their operating funds and thus reduce their already lower standard of living even further. The poor players might invest less than an equal share, hoping that the rich would compensate. Thus, inequity aversion may become a driving motivation (Fehr and Schmidt 1999; Dawes et al. 2007).

A recent review (Raihani and Aitken 2011) discussed how methods from experimental economics can provide insights into both constraints and potentials of human behaviour towards climate mitigation. Wealth heterogeneity has been studied before in threshold public goods games (Rapoport 1988; Rapoport and Suleiman 1993). Our new contribution here is that we investigate the interaction between wealth heterogeneity and meeting intermediate climate targets. With the present experiment we try to study these essential properties of the climate game in isolation from the full complexity of the real situation. Our results can therefore serve as a 'proof of principle' to be followed by future research.

\section{Methods}

57 groups of six subjects each participated in a public goods game (see SOM for demographic information and composition of subject pool), the target of which was to collect at least $€ 120$ in donations from each group ( $€ 20$ per subject, on average). Each subject received in the beginning two amounts of real money, "operating funds" that could be used to contribute toward the collective target and an "endowment", money that was at stake if the collective target was not reached until after round 10. With the operating funds we mimic the money that people can spend for their living or otherwise; the endowment is meant to be any property such as real estate that will be affected by both intermediate climate events and dangerous climate change. In each of 10 rounds each subject could 
choose whether to donate $€ 0, € 2$, or $€ 4$ against the collective target. The decisions of all subjects (pseudonyms) in a round were shown to all subjects after each round. At the end of round 10 , the game software checked whether the collective target of $€ 120$ had been reached by the group. If the collective target was reached, the subjects received the leftovers from their operating funds and their endowment in cash in such a way that their anonymity was not removed. If the collective target was not reached, the subjects received the leftovers from their operating funds - in reality they can use it for enhancing their standard of living before the final collective target has to be reached; however, with $90 \%$ probability the subjects lost their endowment (written instructions for the subjects in Supplementary online material).

We differentiated between "rich" subjects who received $€ 40$ in operating funds and $€ 60$ in endowment, and "poor" subjects who received $€ 20$ in operating funds and $€ 30$ in endowment. The game was played with three different treatments, only rich subjects, only poor subjects, or an even mix of rich and poor subjects. In the mixed treatments subjects were informed by the program who was randomly assigned to be poor or rich and about operating funds and endowment of each player (pseudonym) in the group. Three further treatments had the same definition of rich, poor, or mixed rich-poor, but in addition included the possibility of a "climate event" if the group failed to collect $€ 60$ by the end of round 5 . The climate event could then occur during rounds 6 through 10 , with a probability of $20 \%$ in each of these five rounds, causing the loss of $10 \%$ of both operating fund and endowment. If the group failed to reach the intermediate target of $€ 60$, the expectation value of the number of events occurring was once during the five rounds. Subjects were informed about all these consequences. Thus, the climate event would inflict a palpable though not catastrophic loss on each subject; the event and the criterion for avoiding it mimicked, respectively, intermediate climate damages such as heat waves and droughts some 20 years into the future and the necessity to reach intermediate-term GHG emissions reductions by that time, in order to prevent dangerous climate change later.

\section{Experimental results}

\subsection{Without intermediate target to be reached}

When no intermediate climate target was announced, groups consisting of 6 rich subjects invested on average close to or more than $€ 12$ on average per round (the average needed to reach the collective target), whereas groups of 6 poor subjects invested increasingly less. Mixed groups consisting of 3 poor and 3 rich subjects were intermediate (Fig. 1a). All rich groups, no poor group, and $60 \%$ of the mixed groups reached the collective final target and prevented simulated dangerous climate change (third columns in SOM-Fig. 1b, a, and c, respectively). Subjects of these groups received their endowment plus what they had not spent from their operating funds. Although the rich invested more than the poor both when among themselves (Fig. 2b, c, Mann-Whitney $u$-test, $z=-3.388, n_{1}=8$ groups, $n_{2}=8$ groups, we treat groups as statistical units throughout, $P=0.0007)$ and combined with poor subjects (Fig. 2a, Wilcoxon signed rank matched pairs test, $z=-2.749, n=12, P=0.006$ ), they did not invest differently in mixed groups than when among themselves (Mann-Whitney $u$-test, $z=$ $-0.156, n_{1}=12, n_{2}=8, p=0.88$ ) nor did the poor (Mann-Whitney $u$-test, $z=-0.773, n_{1}=12$, $n_{2}=8, P=0.44$ ). Potentially emotion driven decision rules including spite, inequity aversion, etc. may be difficult to overcome rationally under these conditions (see SOM for a discussion). 
Fig. 1 Money (€) invested per group against the climate target. Mean investment per group of 6 poor subjects (blue), 6 rich subjects (red) and mixed groups consisting of 3 poor and 3 rich subjects (green) in each of 10 rounds of the climate game; hatched line depicts the investment per round that is needed to reach the final climate target; a without intermediate climate target announced; b with intermediate climate target announced

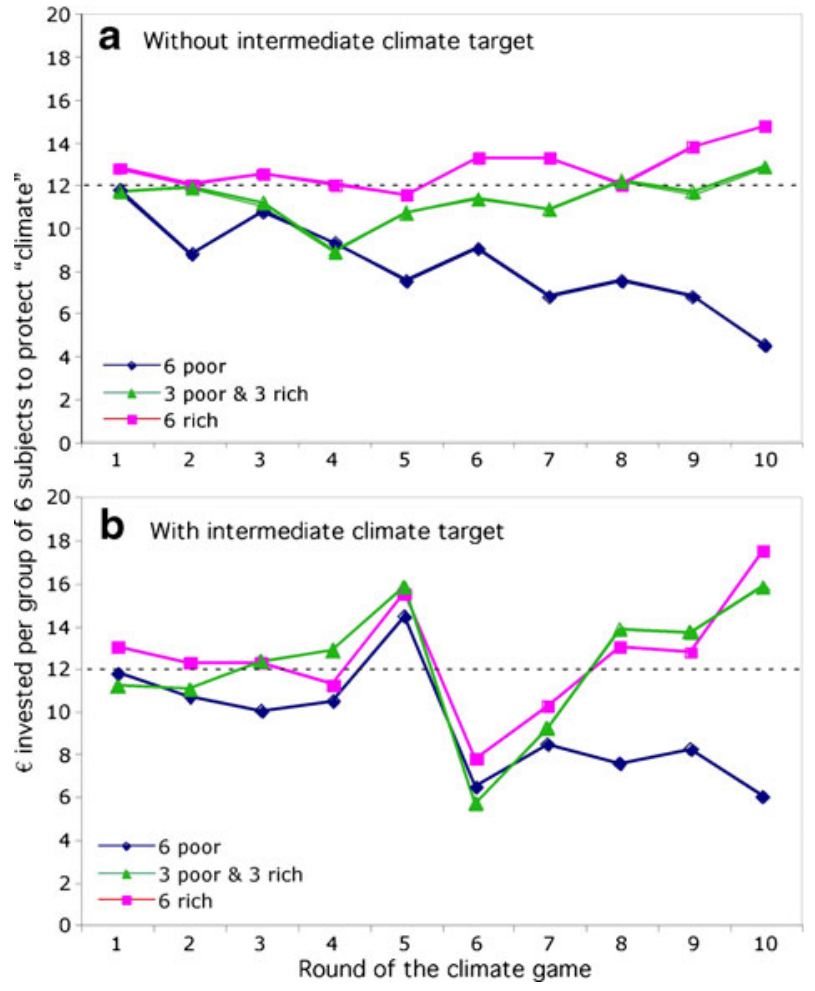

3.2 With intermediate target to be reached

When an intermediate target had to be reached, that is, $€ 60$ had to be collected until the end of round 5 to prevent climate events in the following 5 rounds, the dynamics of investment changed completely (Fig. 1b): all types of groups invested at a high level peaking in round 5; thereafter investments dropped and recovered in rich and mixed group in a similar way, but remained low in the poor groups. Nevertheless, 3 out of 9 poor groups met the final target, all rich groups and 2/3 of the mixed groups (column 4 in Fig. SOM-1a, b, and c), although absolute investments of the mixed groups were very close to those of the rich groups (Fig. 1b). Now mixed groups that did not reach the final target of $€ 120$ came closer $(€ 113, n=5)$ than without intermediate target $(€ 97.2, n=4)$. The intermediate target was met by $60 \%$ of the poor groups, all rich groups and almost all mixed groups (column 2 in SOMFig. 1a, b, c). Compared to the situation without an intermediate target the increase was significant both in poor groups $(P=0.03$, Fisher exact test) and in mixed groups $(P=0.0006$, Fisher exact test). In poor, but not in rich groups, absolute investments increased significantly until round 5, compared to the treatment without announcement of the intermediate target (Fig. 3b, e, Mann-Whitney $u$-test, $z=-2.314, n_{1}=8, n_{2}=9, P=0.021$ ). Although the poor did not invest differently alone (Fig. 2e) and together with the rich (Fig. 2d), the rich gave more when mixed with the poor (Fig. 2d), than when among themselves (Fig. 2f), both until round 5 (Mann-Whitney $u$-test, $z=-2.211, n_{1}=12, n_{2}=8$, $P=0.027$ ) and until round 10 (Mann-Whitney $u$-test, $z=-2.978, n_{1}=12, n_{2}=8, P=0.003$ ). These results suggest that the rich compensated in mixed groups the lower investment capability of the poor, however, only when an intermediate target was announced. 
Fig. 2 Money (€) invested per sub-group of 3 subjects in each of the 3 treatments. a-c without intermediate climate target announced and of the 3 treatments; $\mathbf{d}-\mathbf{e}$ with intermediate climate target announced until end of round 5 (light columns) and until end of round 10 (whole columns). Columns depict means + s.e. Stippled line at intermediate target of $€ 30$ (for 3 subjects), hatched line at final target of $€ 60$ (for 3 subjects). a, d 3 poor \& 3 rich subjects; b, e 3 poor subjects (half the investment of groups of 6 poor subjects); $\mathbf{c}, \mathbf{f}$ 3 rich subjects (half the investment of groups of 6 rich subjects)

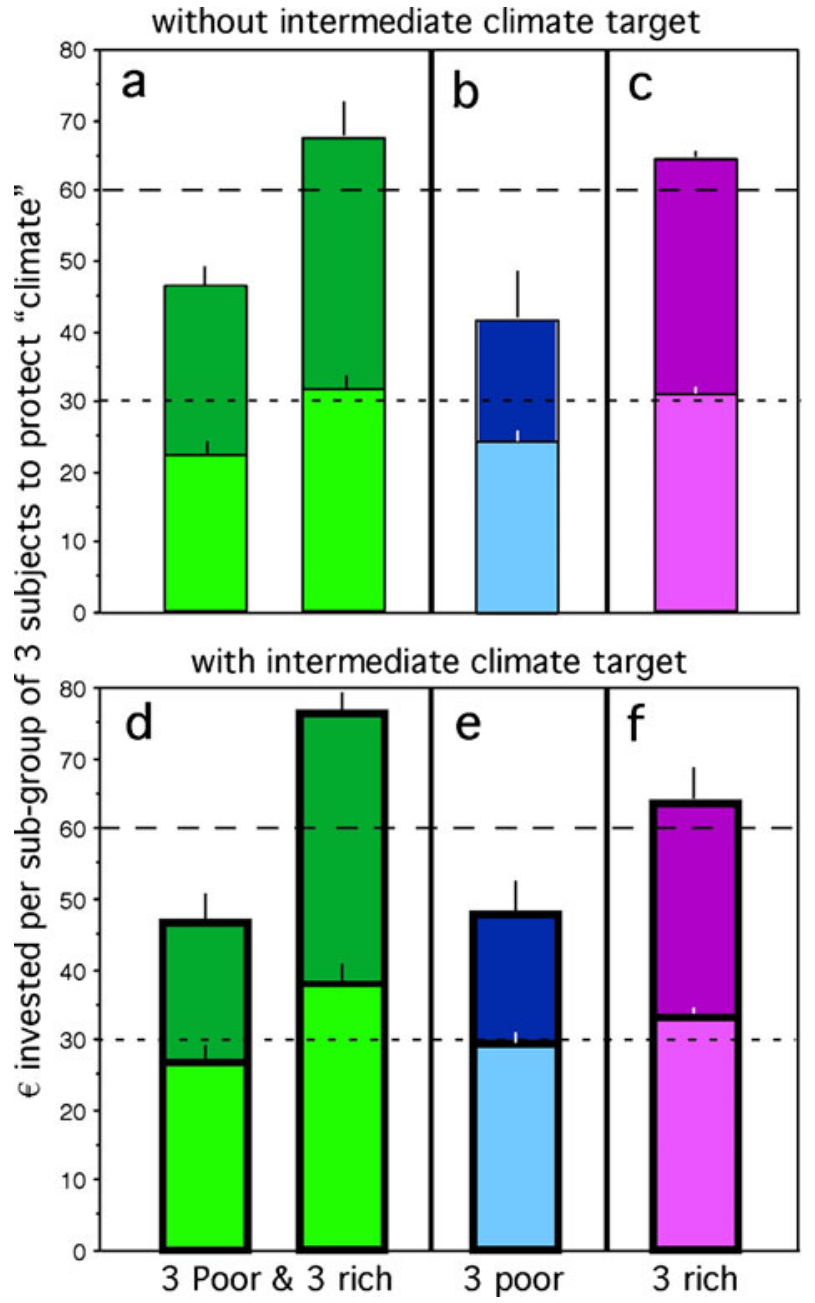

3.3 A successful interaction between the rich and the poor

We find a significant regression of the investment of poor groups on the investment of rich groups in the first 5 rounds (Fig. $3 b, F$-test $=56.691, P=0.0001$ ) with intermediate target announced but not without this announcement (Fig. 3a, $F$-test $=1.183, P=0.30$ ). This close negative correlation between the investments of rich and poor with intermediate target announced, suggests that the rich compensate what is missing from the poor subjects' investment.

\section{Discussion and conclusions}

Protecting the global climate is an example of the "tragedy of the commons" (Hardin 1968; Inman 2009). The essential problems of the global climate change "game" can be studied with the collective-risk social dilemma (Milinski et al. 2008). Adding more realism to this 
Fig. 3 Rich interact with poor during the first 5 rounds. Regression of money $(€)$ invested by each sub-group of 3 poor subjects on money $(€)$ invested by each sub-group of 3 rich subjects; a without intermediate climate target announced; b with intermediate climate target announced. Larger dot contains 2 data points. See text for statistics

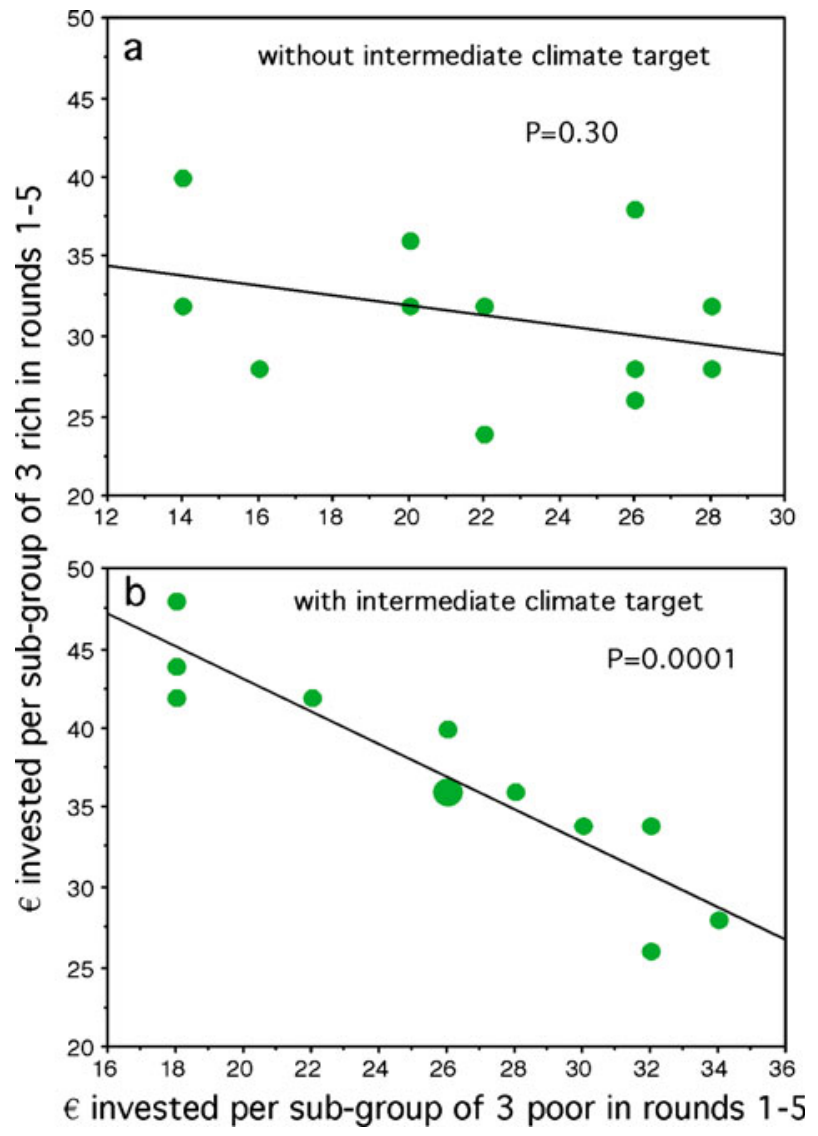

game by both including the interaction of poor and rich players and the necessity of preventing intermediate costly climate risks by meeting intermediate targets had the surprising effect that the intermediate collective target was easily reached through enhanced cooperation.

The most realistic treatment-combination of rich and poor-showed that the announcement of an intermediate target led to significantly enhanced cooperation during the first 5 rounds. The rich sub-group readily used their greater economic power to make sure the intermediate target was reached, especially when the poor invested only little. Although the final target was reached on average, it was missed by a third of the mixed groups who, however, came closer to the final target than did mixed groups without intermediate target announced.

Our experiments were designed to simulate the interaction of rich and poor countries in climate negotiations - a conflict dominating many of the deliberations at COP15 - and the existence of two separate time horizons in climate negotiations: intermediate GHG emissions reduction targets until year 2020 such as discussed in the Copenhagen Accord (UNFCCC 2009), and the $>50 \%$ reduction target until year 2050 implied by the $2{ }^{\circ} \mathrm{C}$ target and the associated imperative to avoid dangerous climate change (Schneider 2001). Our experiments point to the crucial role played by the compatibility of timescales of planning and consequences; if one accepts our round 5 as corresponding to year 2020 and our round 10 to year 2050, we demonstrate that in principle long-term rational behaviour requiring cooperation is much harder to obtain than short-term rational cooperative behaviour. 
All our subjects came from Western, educated, industrialized, rich and democratic (WEIRD, see Henrich et al. 2010) societies. This should not compromise external validity for cases when the students acted as "rich", including the compensation by the rich of missing contributions by the poor in the combination of rich and poor with the announcement of an intermediate target. It is, however, possible that WEIRD subjects acting as "poor" in the experiment behaved differently than subjects actually from developing nations would have, who probably would contribute even less. It would be a challenge for a future study to repeat the experiment with European students allocated to "rich" and students from developing countries to "poor".

In reality climate responds to the concentrations of GHG, implying a delay of several decades between GHG emissions reductions and the avoidance of climate change impacts. While this delay is an important complication in the perception of and response to climate change (Sterman and Sweeney 2007; Sterman 2008), the much greater readiness of our players to respond to climate targets and risks if they are intermediate rather than long-term underscores the importance of investigating near-term climate change. The IPCC has already responded to this importance by including in its Fifth Assessment Report a new chapter on climate change over the next 20-30 years (IPCC_WGI 2010). Awareness of near-term climate change is likely to influence decisions, as indicated by the recognition that people who have experienced a climate event express a greater willingness to save energy (Spence et al. 2011). Our experimental results provide evidence that a near-term connection between climate risks and climate change mitigation planning is a necessary, though not sufficient, component of successful climate negotiations.

Acknowledgements We thank the students at Hamburg, Kiel and Münster University for their participation, P. Altrock, H. Brendelberger, E. Bornberg-Bauer, S. Dobler, S. Milinski, P. Tudzynski, F. Weinreich and B. Wölfing for support, and two reviewers for constructive comments.

Open Access This article is distributed under the terms of the Creative Commons Attribution Noncommercial License which permits any noncommercial use, distribution, and reproduction in any medium, provided the original author(s) and source are credited.

\section{References}

Anonymous (2009) After Copenhagen. Nature 462:957-958

Dawes CT, Fowler JH, Johnson T, McElreath R, Smirnov O (2007) Egalitarian motives in humans. Nature 446:794-796

Fehr E, Schmidt KM (1999) A theory of fairness, competition, and cooperation. Quart J Econ 114:817-868 Hardin G (1968) The tragedy of the commons. Science 162:1243-1248

Henrich H, Heine SJ, Norenzayan A (2010) Most people are not WEIRD. Nature 466:29

Inman M (2009) The climate change game. Nat Rep Clim Change 3:130-133

IPCC WGI (2010) Chapter outline: working group I contribution to the IPCC fifth assessment report. http:// www.ipcc-wg1.unibe.ch/AR5/chapteroutline.html

Meehl GA, Stocker TF, Collins WD, Friedlingstein P, Gaye AT, Gregory JM, Kitoh A, Knutti R, Murphy JM, Noda A, Raper SCB, Watterson IG, Weaver AJ, Zhao Z-C (2007) Global climate projections. In: Solomon S, Qin D, Manning M, Chen Z, Marquis M, Averyt KB, Tignor M, Miller HL (eds) Climate change 2007: the physical science basis. Contribution of working group I to the fourth assessment report of the intergovernmental panel on climate change. Cambridge University Press, Cambridge, pp 747-845

Meinshausen M, Meinshausen N, Hare W, Raper SCB, Frieler K, Knutti R, Frame DJ, Allen MR (2009) Greenhouse-gas emission targets for limiting global warming to 2 degrees C. Nature 458:1158-1162

Milinski M, Sommerfeld RD, Krambeck H-J, Reed FA, Marotzke J (2008) The collective-risk social dilemma and the prevention of simulated dangerous climate change. Proc Natl Acad Sci USA 105:22912294 
Raihani N, Aitken D (2011) Uncertainty, rationality and cooperation in the context of climate change. Clim Change 108:47-55. doi:10.1007/s10584-10010-10014-10584

Rapoport A (1988) Provision of step-level public-goods - effects of inequality in resources. J Person Soc Psych 54:432-440

Rapoport A, Suleiman R (1993) Incremental contribution in step-level public-goods games with asymmetric players. Org Beh Hum Dec Proc 55:171-194

Roeckner E, Giorgetta MA, Crueger T, Esch M, Pongratz J (2010) Historical and future anthropogenic emission pathways derived from coupled climate-carbon cycle simulations. Clim Change. doi:10.1007/ s10584-10010-19886-10586

Santos FC, Pacheco JM (2011) Risk of collective failure provides an escape from the tragedy of the commons. Proc Natl Acad Sci USA 108:10421-10425

Schneider SH (2001) What is 'dangerous' climate change? Nature 411:17-19

Spence A, Poortinga W, Butler C, Pidgeon NF (2011) Perceptions of climate change and willingness to save energy related to flood experience. Nat Clim Change 1:1-4

Sterman JD (2008) Economics - risk communication on climate: mental models and mass balance. Science 322:532-533

Sterman JD, Sweeney LB (2007) Understanding public complacency about climate change: adults' mental models of climate change violate conservation of matter. Clim Change 80:213-238

UNFCCC (2009) Copenhagen Accord. http://unfccc.int/resource/docs/2009/cop15/eng/107.pdf 